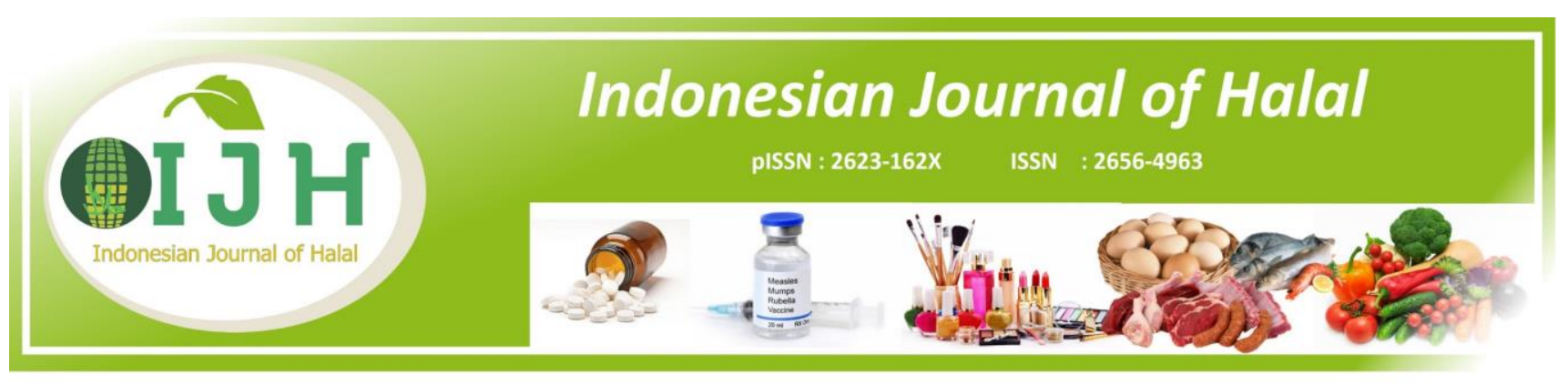

\title{
Analisis Kualitatif dan Kuantitatif Kandungan Boraks Pada Bakso Menggunakan Kertas Turmerik, FT - IR Spektrometer dan Spektrofotometer Uv -Vis
}

\author{
Dedy Suseno ${ }^{1 *}$ \\ ${ }^{1)}$ Halal Research Center Universitas YARSI \\ Jl. Letjend Soeprapto Kav 13 Cempaka Putih, Jakarta Pusat \\ Telp/fax :(021) 4206674/ (021) 4243171 \\ ${ }^{*}$ Penulis korespondensi: dedy.suseno @yarsi.ac.id
}

\begin{abstract}
Abstrak
Bakso merupakan salah satu makanan yang banyak dikonsumsi karena penyajiannya yang praktis, memiliki harga yang terjangkau dan banyak tersedia diberbagai tempat seperti pasar tradisional, pasar swalayan dan masih banyak lagi. Banyaknya masyarakat yang mengonsumsi bakso membuat para pedagang berlomba-lomba membuat bakso yang enak, namun dengan alasan kualitas dan awet ada pedagang yang menggunakan boraks sebagai bahan tambahan pangan. Boraks merupakan senyawa kimia yang mengandung unsur Boron (B) dan memiliki nama dagang bleng, pijer atau gendar. Boraks biasa digunakan sebagai bahan solder, pembuatan gelas, bahan pembersih/pelicin porselin, pengawet kayu dan antiseptik kayu. Penelitian terhadap bakso dikota Medan menunjukkan bahwa 8 dari 10 sampel bakso yang diperiksa ternyata mengandung boraks dengan konsentrasi $0,08 \%-0,29 \%$. Menurut Peraturan Menteri Kesehatan RI No 033 tahun 2012 tentang bahan tambahan pangan, boraks merupakan salah satu dari jenis bahan tambahan pangan yang dilarang digunakan dalam produk makanan. Tujuan penelitian ini adalah mengidentifikasi adanya boraks pada bakso sapi secara kualitatif maupun kuantitatif. Hasil analisis boraks menggunakan kertas turmerik menunjukkan bahwa perubahan warna pada kertas turmerik hanya terjadi pada kontrol positif saja sedangkan analisis boraks menggunakan FTIR Spektrometer semua sampel dan kontrol positif tidak menunjukkan adanya spektrum sidik jari pada bilangan gelombang 1500 sampai $1000 \mathrm{~cm}-1$. Hasil analisis boraks menggunakan spektrofotometer Uv-Vis menunjukkan bahwa 9 dari 12 positif mengandung boraks dengan konsentrasi terbesar pada sampel B1 sebesar $2414.375 \mu \mathrm{g} / \mathrm{mL}$.
\end{abstract}

Kata kunci: Boraks, Bakso, FT - IR Spektrometer, Kertas Turmerik

\begin{abstract}
Qualitative and Quantitative Analysis of Borax Content in Meatballs Using Turmeric Paper, FTIR Spectrometers and Uv-Vis Spectrophotometers. Meatballs are one of the most consumed foods because of their practical presentation, have affordable prices and are widely available in various places such as traditional markets, supermarkets and much more. Many people who consume meatballs make traders compete to make tasty meatballs, but for quality and durable reasons there are traders who use borax as food additives. Borax is a chemical compound containing Boron (B) and has a trade name bleng, pijer or gendar. Borax is commonly used as soldering material, glass making, porcelain cleaning/lubricating agents, wood preservatives and wood antiseptics. Research on meatballs in the city of Medan showed 8 of the 10 meatball samples containing borax with a concentration of $0.08 \%-0.29 \%$. According to RI Minister of Health Regulation No. 033 of 2012 concerning food additives, borax is one of the types of food additives used for food products. The purpose of this study is a publication about the participation of borax on beef meatballs qualitatively and quantitatively. The results of borax
\end{abstract}


analysis using turmeric paper showed that the color changes on turmeric paper only occurred in positive controls, whereas borax analysis using FTIR spectrometers, all samples and positive controls did not indicate the presence of fingerprints at wave numbers 1500 to $1000 \mathrm{~cm}-1$. The results of the borax analysis using a Uv-Vis spectrophotometer showed 9 out of 12 were positive containing borax with the largest concentration in the B1 sample of $2414.375 \mu \mathrm{g} / \mathrm{mL}$.

Keywords: kaedah, ushuliyah, istinbath, ijtihad

\section{PENDAHULUAN}

Keamanan pangan merupakan salah satu masalah yang harus mendapatkan perhatian terutama di negara berkembang seperti Indonesia, karena bisa berdampak buruk terhadap kesehatan. Penyebabnya adalah masih rendahnya pengetahuan, keterampilan, dan tanggung jawab produsen pangan terhadap mutu dan keamanan makanan terutama pada industri kecil atau industri rumah tangga. Untuk mendapatkan makanan seperti yang diinginkan maka sering pada proses pembuatannya ditambahkan bahan tambahan yang lebih dikenal dengan sebutan bahan tambahan pangan (BTP) atau food additive (Widyaningsih 2006). BTP ditambahkan untuk memperbaiki karakter pangan agar memiliki kualitas yang meningkat. BTP pada umumnya merupakan bahan kimia yang telah diteliti dan diuji sesuai dengan kaidah-kaidah ilmiah yang ada. Ada kalanya hanya untuk mendapatkan laba yang banyak atau bahan pangan yang dijual tidak cepat basi, para produsen ada yang menambahkan bahan kimia berbahaya ke dalam bahan pangan. Padahal bahan kimia tersebut jika ditambahkan akan membahayakan kesehatan bagi konsumen yang mengkonsumsinya.

Boraks adalah senyawa kimia turunan dari logam berat Boron (B), Boraks merupakan antiseptik dan pembunuh kuman. Bahan ini banyak digunakan sebagai bahan anti jamur, pengawet kayu, dan antiseptik pada kosmetik (Svehla 1985 dalam Widayat 2011). Menurut Peraturan Menteri Kesehatan RI No 033 tahun 2012 tentang bahan tambahan pangan, boraks merupakan salah satu dari jenis bahan tambahan pangan yang dilarang digunakan dalam produk makanan. Dampak buruk dari mengkonsumsi boraks yaitu menyebabkan iritasi saluran cerna, yang ditandai dengan sakit kepala, pusing, muntah, mual, dan diare. Gejala lebih lanjut ditandai dengan badan menjadi lemas, kerusakan ginjal, bahkan shock dan kematian bila tertelan $5-10 \mathrm{~g} / \mathrm{kg}$ berat badan.

Bakso banyak dikonsumsi karena penyajiannya yang praktis dan banyak tersedia diberbagai tempat seperti pasar tradisional, pasar swalayan, dan masih banyak lagi, serta dijual dengan jenis dan harga yang terjangkau bagi semua kalangan masyarakat namun beberapa publikasi menyebutkan bahwa boraks sering digunakan sebagai pengenyal dan pemberi rasa gurih. Badan Pengawas Obat dan Makanan menyatakan bahwa bila boraks diberikan pada bakso akan membuat bakso tersebut sangat kenyal, warna cenderung agak putih dan memiliki rasa gurih, sedangkan pada kerupuk yang mengandung boraks akan memiliki tekstur sangat renyah dan rasanya getir. Kurangnya edukasi dan harganya yang murah menyebabkan para produsen nakal lebih memilih menggunakan boraks sebagai bahan tambahan makanan tanpa melihat efek buruk yang akan terjadi kepada konsumen.

Penelitian terhadap bakso dikota Medan dari 10 sampel bakso menunjukkan bahwa $80 \%$ dari sampel yang diperiksa ternyata mengandung boraks (delapan sampel dari sepuluh sampel) dan kadar boraks yang di dapat dalam bakso antara 0,08\% - 0,29\% (Panjaitan 2010). Rumanta (2014) menyatakan bahwa uji kualitas jajanan pasar berupa lontong, bakso dan mie basah di pasar Pamulang telah menunjukkan adanya boraks pada sampel tersebut. Adanya data produsen yang menggunakan boraks pada bahan tambahan makanan menimbulkan kekhawatiran bagi para konsumen untuk mengkonsumsi makanan terutama bakso, lontong dan mie basah. Walaupun masih dalam konsentrasi yang rendah temuan boraks dalam makanan, namun jika terus menerus terakumulasi pada tubuh akan menyebabkan kerusakan organ tubuh. Tujuan penelitian ini untuk mengetahui keberadaan boraks pada produk makanan terutama bakso yang dijual di pasaran dan di lingkungan kampus YARSI Jakarta secara kualitatif dan kuantitatif.

\section{BAHAN DAN METODE Bahan dan Alat}

Bahan-bahan yang digunakan yaitu sampel bakso, kunyit, alkohol 70\%, akuades, asam sulfat pekat (Merck), asam asetat glasial (Merck), Etanol (Merck), standar curcumin (Merck), standar boraks (Na2B2O7. 10H2O).

Alat-alat yang digunakan meliputi batang pengaduk, labu Erlenmeyer, FT - IR spektrometer, oven, gelas piala, gelas ukur, labu ukur, mortar, termometer, blender, spektrofotometer, sentrifusa.

\section{Metode Penelitian}

Preparasi sampel

Pengambilan sampel dilakukan dengan menggunakan metode Simple Random Sampling. Sampel bakso yang telah diambil kemudian dikemas dalam wadah plastik kering dan diberi kode sesuai dengan tempat pengambilan sampel. Sampel bakso dibawa ke laboratorium untuk dilakukan pengujian terhadap kandungan boraksnya.

Kontrol positif dan negatif sampel bakso adalah bakso yang dibuat sendiri. Pada kontrol negatif bahan yang digunakan sama dengan bahan pembuatan bakso 
pada umumnya dan tanpa penambahan boraks namun pada kontrol positif, bahan pembuatan bakso ditambahkan boraks dengan konsentrasi $10 \mathrm{~g} / \mathrm{kg}$ bahan.

\section{Pembuatan Alat Pendeteksi Boraks Menggunakan Kertas Turmerik}

Proses pembuatan deteksi boraks ini diawali dengan mengupas kunyit lalu dicuci dan diparut. Air kunyit yang didapatkan lalu ditampung dan diukur menggunakan gelas ukur. Tambahkan sebanyak $10 \%$ alkohol $70 \%$ dari total volume air kunyit yang didapatkan. Ambil kertas saring, gunting persegi ukuran 8 x $8 \mathrm{~cm}$ dan celupkan dalam air kunyit, bolak balik menggunakan pinset sampai merata pada seluruh permukaan kertas saring. Kertas ini lalu diletakkan pada Loyang dan diangin-anginkan agar kering (Hartati 2017)

\section{Analisis boraks secara kualitatif dengan kertas} Turmerik

Sampel sebanyak $1 \mathrm{~g}$ ditimbang lalu ditambahkan akuades sebanyak 1 : 10. Campuran ini lalu diblender sampai halus dan disaring menggunakan kertas saring. Cairan yang didapatkan ditempatkan dalam gelas piala. Celupkan kertas Turmerik selama 1-2 menit ke dalam cairan sampel, bila kertas turmerik berubah warna menjadi merah kecoklatan maka sampel positif mengandung boraks (Hartati 2017).

\section{Analisis boraks secara kualitatif dengan FT - IR Spektrometer}

Sebelum menganalisis ada atau tidaknya boraks dalam sampel bakso maka diperlukan isolasi boraks dalam sampel tersebut. Isolasi boraks dalam sampel bakso mengacu pada penelitian Panjaitan (2010). Sebanyak 5 gram sampel bakso ditambah dengan $20 \mathrm{~mL}$ akuades lalu diblender sampai halus. Setelah diblender, sampel tersebut dimasukkan ke dalam tabung sentrifusa. Proses sentrifugasi dilakukan selama 2 menit dengan kecepatan 3000rpm. Bagian supernatannya diambil dengan cara disaring dengan kertas saring. Supernatan yang didapatkan akan digunakan untuk analisis boraks secara kualitatif. Sebanyak $20 \mu \mathrm{L}$ supernatan dipipet lalu ditempatkan dalam kristal germanium pada alat FT-IR Spektrometer. Pembacaan dilakukan pada scan 32 resolusi 4 dan menggunakan bilangan gelombang 4000 sampai $500 \mathrm{~cm}^{-1}$. Hasil spektrum yang didapatkan akan dibandingkan dengan spektrum $\mathrm{Na}_{2} \mathrm{~B}_{2} \mathrm{O}_{7} \cdot 10 \mathrm{H}_{2} \mathrm{O}$ pada konsentrasi $105 \mu \mathrm{g} / \mathrm{mL}, 8 \times 104 \mu \mathrm{g} / \mathrm{mL}, 6 \times 104 \mu \mathrm{g} / \mathrm{mL}$, $4 \times 104 \mu \mathrm{g} / \mathrm{mL}$, dan $2 \times 104 \mu \mathrm{g} / \mathrm{mL}$

\section{Analisis boraks secara kualitatif dengan Spektrofotometer}

Sebelum menganalisis ada atau tidaknya boraks dalam sampel bakso maka diperlukan isolasi boraks dalam sampel tersebut. Isolasi boraks dalam sampel bakso mengacu pada penelitian Panjaitan (2010).
Sebanyak 5 gram sampel bakso ditambah dengan 20 $\mathrm{mL}$ akuades lalu diblender sampai halus. Setelah diblender, sampel tersebut dimasukkan ke dalam tabung sentrifusa. Proses sentrifugasi dilakukan selama 2 menit dengan kecepatan 3000 rpm. Bagian supernatannya diambil dengan cara disaring dengan kertas saring. Supernatan yang didapatkan akan digunakan untuk analisis boraks secara kuantitatif dengan spektrofotometer.

Penentuan Panjang Gelombang Maksimum dan Pembuatan Kurva Standar Boraks

Larutan induk boraks dibuat dengan menimbang $50 \mathrm{mg}$ serbuk boraks yang kemudian dilarutkan dengan $100 \mathrm{~mL}$ akuades sehingga konsentrasi larutan menjadi $500 \mu \mathrm{g} / \mathrm{mL}$. Larutan induk boraks $500 \mu \mathrm{g} / \mathrm{mL}$ tersebut diencerkan menjadi konsentrasi $5 \mu \mathrm{g} / \mathrm{mL}, 10 \mu \mathrm{g} / \mathrm{mL}, 20$ $\mu \mathrm{g} / \mathrm{mL}, 30 \mu \mathrm{g} / \mathrm{mL}, 60 \mu \mathrm{g} / \mathrm{mL}$ dan $80 \mu \mathrm{g} / \mathrm{mL}$ dengan menambahkan akuades. Selanjutnya sebanyak $0,5 \mathrm{~mL}$ larutan boraks dari masing-masing konsentrasi yang sudah dibuat dimasukkan ke dalam cawan porselin dan ditambah $0,5 \mathrm{~mL}$ larutan $\mathrm{NaOH} 10 \%$ Cawan ini kemudian dipanaskan di atas penangas air sampai larutan kering. Pemanasan dilanjutkan dengan oven pada suhu $1000 \pm 50 \mathrm{C}$ selama 5 menit. Larutan ditambah 1,5 mL larutan kurkumin $0,125 \%$ lalu dipanaskan sambil diaduk selama \pm 3 menit. Setelah dingin larutan ditambah 1,5 mL larutan asam sulfat dan asam asetat (1:1), sambil diaduk sampai tidak ada warna kuning baik pada cawan maupun pada pengaduk lalu didiamkan selama \pm 8 menit. Larutan ditambah sedikit etanol kemudian disaring dengan kertas saring lalu dimasukkan ke dalam labu ukur $25 \mathrm{~mL}$ dan diencerkan dengan etanol sampai garis tanda.

Untuk penentuan panjang gelombang maksimum digunakan pada larutan standar boraks $5 \mu \mathrm{g} / \mathrm{mL}$ dari boraks murni. Larutan ini diamati serapannya pada panjang gelombang antara 400 sampai $600 \mathrm{~nm}$ pada alat spektrofotometer UV-VIS (Panjaitan 2010). Penentuan kurva standar boraks dilakukan dengan mengukur nilai serapannya pada panjang gelombang maksimum yang telah diperoleh. Konsentrasi boraks yang digunakan yaitu $5 \mu \mathrm{g} / \mathrm{mL}, 10 \mu \mathrm{g} / \mathrm{mL}, 20 \mu \mathrm{g} / \mathrm{mL}$, $30 \mu \mathrm{g} / \mathrm{mL}, 60 \mu \mathrm{g} / \mathrm{mL}$ dan $80 \mu \mathrm{g} / \mathrm{mL}$.

\section{Penentuan Kadar Boraks pada Sampel Bakso}

Supernatan hasil isolasi boraks dalam sampel bakso dipipet sebanyak $0,5 \mathrm{~mL}$ lalu ditambahkan sebanyak $0,5 \mathrm{~mL}$ larutan $\mathrm{NaOH} 10 \%$ dalam cawan porselin. Cawan ini kemudian dipanaskan di atas penangas air sampai larutan kering. Pemanasan dilanjutkan dengan oven pada suhu $1000 \pm 50 \mathrm{C}$ selama

5 menit. Setelah kering, kedalam cawan porselin tersebut ditambahkan 1,5 mL larutan kurkumin 0,125\% dan dipanaskan sambil diaduk selama \pm 3 menit. Setelah dingin, kedalam cawan tersebut ditambahkan 1,5 mL larutan asam sulfat dan asam asetat (1:1), sambil diaduk sampai tidak ada warna kuning baik pada cawan maupun pada pengaduk lalu diamkan selama \pm 
8 menit. Larutan yang terbentuk lalu ditambah sedikit etanol absolut kemudian disaring dengan kertas saring lalu dimasukkan ke dalam labu ukur $25 \mathrm{~mL}$ dan diencerkan dengan etanol sampai garis tanda. Hasil saringan larutan yang sudah dipreparasi tersebut dikumpulkan dan diamati serapannya pada panjang gelombang $428 \mathrm{~nm}$ pada alat spektrofotometer UVVIS.

\section{HASIL DAN PEMBAHASAN}

Hasil Uji Kualitatif Boraks Dengan Kertas Turmerik

Kertas turmerik yang dihasilkan dengan menggunakan ekstrak kunyit menghasilkan warna kuning pada kertas saringnya. Jika sampel mengandung boraks maka akan terjadi perubahan warna pada kertas turmerik dari kuning menjadi coklat kemerahan. Warna coklat kemerahan ini merupakan warna dari kompleks boron-kurkumin yaitu rososianin (Halim dan Azhar 2012). Adanya boraks pada makanan khususnya bakso merupakan suatu pelanggaran dalam proses produksi makanan olahan. Hal ini sesuai dengan SNI 01 -3818 1995 tentang syarat bakso daging harus tidak boleh mengandung boraks sedikitpun. Undang-Undang No. 7 tahun 1996 tentang Pangan juga disebutkan bahwa setiap orang yang memproduksi pangan untuk diedarkan dilarang menggunakan bahan apa pun sebagai bahan tambahan pangan yang dinyatakan terlarang atau melampaui ambang batas maksimal yang ditetapkan.

Hasil penelitian menunjukkan bahwa semua sampel yang diuji menggunakan kertas nurmerik tidak mengandung boraks. Hasil positif hanya didapatkan pada kontrol positif yang ditandai dengan adanya perubahan warna kertas turmerik dari kuning menjadi coklat. Selain kontrol positif, digunakan pula larutan standar boraks murni dengan konsentrasi $3000 \mu \mathrm{g} / \mathrm{mL}$. Hasil menunjukkan bahwa kertas turmerik yang dibuat mampu membaca boraks pada konsentrasi tersebut yang ditunjukkan dengan adanya perubahan warna kertas turmerik dari kuning menjadi merah kecoklatan. Menurut Halim (2012) kurkumin dapat berikatan dengan asam borat yang kemudian akan membentuk komponen rososianin berwarna merah sehingga dapat digunakan sebagai uji deteksi boraks. Hartati (2017) melaporkan bahwa kandungan boraks pada kerupuk "uyel" mampu dideteksi dengan menggunakan kertas kunyit dan setelah dianalisis kuantitatif dengan spektrofotometer UV -Vis didapat konsentrasi boraks sebesar 11.8 ppm. Penelitian Fuad (2014) menyatakan bahwa uji boraks pada sampel dengan menggunakan kertas kunyit yang dibuat sendiri tidak terdapat perubahan warna sedangkan setelah dilakukan analisis kuantitatif menggunakan metode titrasi, boraks dapat terdeteksi pada sampel dengan konsentrasi terendah 103 ppm. Adanya perbedaan dalam hal limit deteksi uji kualitatif menggunakan kertas turmerik pada analisis boraks disebabkan karena perbedaan konsentrasi curcumin yang didapatkan saat ekstraksi kunyit. Adanya kemungkinan perubahan warna pada kertas turmerik yang sangat kecil memungkinkan terdeteksinya boraks dalam sampel, namun karena keterbatasan dalam penglihatan diperlukan analisis kuantitatif agar hasilnya terlihat jelas dan tepat.

Tabel 1 Hasil Uji Kualitatif Sampel Menggunakan Kertas Turmerik

\begin{tabular}{llll}
\hline Nomor & Kode Sampel & Keterangan & Hasil Uji Kualitatif \\
\hline 1 & A1 & Pasar Cempaka Putih & - \\
\hline 2 & A2 & Pasar Cempaka Putih & - \\
\hline 3 & A3 & Pasar Cempaka Putih & - \\
\hline 5 & A4 & Pasar Cempaka Putih & - \\
\hline 6 & A5 & Pasar Cempaka Putih & - \\
\hline 7 & B1 & Sekitar Kampus YARSI & - \\
\hline 8 & B2 & Sekitar Kampus YARSI & - \\
\hline 9 & B3 & Sekitar Kampus YARSI & - \\
\hline 10 & B4 & Sekitar Kampus YARSI & - \\
\hline 11 & B5 & Sekitar Kampus YARSI & - \\
\hline 12 & B6 & Sekitar Kampus YARSI & - \\
\hline 13 & K- & Sekitar Kampus YARSI & - \\
\hline 14 & K+ & Kontrol - & + \\
\hline
\end{tabular}

Ket : $(-)$ = tidak mengandung boraks,$(+)=$ mengandung boraks 


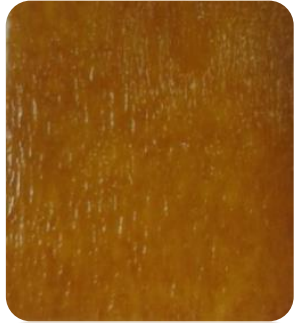

(a)

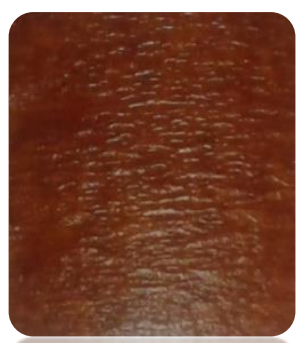

(b)

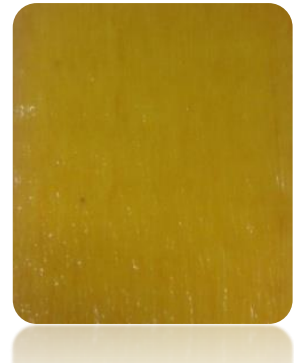

(c)

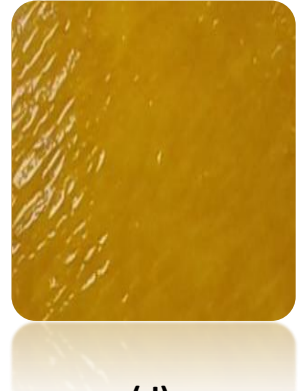

(d)

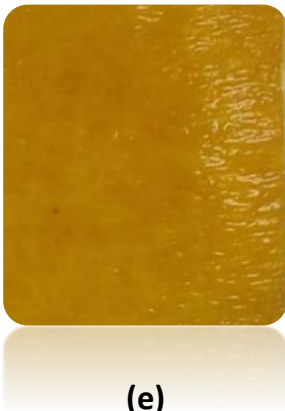

(e)

Gambar $1 \quad$ Hasil uji kualitatif menggunakan kertas turmerik. (a) kontrol positif, (b) Standar boraks

3000 $\mu \mathrm{g} / \mathrm{mL}$, (c) kontrol negatif, (d) sampel A2, (e) sampel B1

\section{Hasil Uji Kuantitatif Boraks Pada Sampel}

Panjang gelombang maksimum dan kurva standar boraks diperlukan untuk mencari konsentrasi boraks dalam sampel. Panjang gelombang maksimum ini menggambarkan panjang gelombang yang memiliki nilai serapan yang maksimum pada rentang $400-600$ $\mathrm{nm}$. Berdasarkan percobaan didapatkan nilai panjang gelombang maksimum sebesar $428 \mathrm{~nm}$. Penelitian
Kresdinapayana (2017) menyatakan bahwa nilai panjang gelombang maksimum yang didapatkan sebesar $550.4 \mathrm{~nm}$.

Persamaan regresi yang didapatkan dari pembacaan standar boraks berbagai konsentrasi yaitu $\mathrm{Y}=0.002 \mathrm{X}+0.003$ dengan nilai $\mathrm{R}^{2} 0.998$. Berdasarkan persamaan tersebut konsentrasi boraks dari sampel bisa teridentifikasi.

Tabel 2 Hasil Uji kuantitaif boraks pada sampel menggunakan spektrofotometer UV-Vis

\begin{tabular}{llll}
\hline Nomor & Kode Sampel & Keterangan & Hasil Uji Kuantitatif $(\mu \mathrm{g} / \mathrm{mL})$ \\
\hline 1 & A1 & Pasar Cempaka Putih & 131.875 \\
2 & A2 & Pasar Cempaka Putih & 1467.5 \\
3 & A3 & Pasar Cempaka Putih & 0 \\
4 & A4 & Pasar Cempaka Putih & 186.25 \\
5 & A5 & Pasar Cempaka Putih & 512.5 \\
6 & B1 & Sekitar Kampus YARSI & 2414.375 \\
7 & B2 & Sekitar Kampus YARSI & 129.375 \\
8 & B3 & Sekitar Kampus YARSI & 450 \\
9 & B4 & Sekitar Kampus YARSI & 262.5 \\
10 & B5 & Sekitar Kampus YARSI & 222.5 \\
11 & B6 & Sekitar Kampus YARSI & 0 \\
12 & B7 & Sekitar Kampus YARSI & 0 \\
13 & K- & Kontrol - & 0 \\
14 & K+ & Kontrol + & 3261.875 \\
\hline
\end{tabular}

Boraks dalam bentuk asam borat akan terikat oleh kurkumin sehingga membentuk kompleks Boron Cyanon Kurkumin yang berwarna merah cherry. Kompleks warna tersebutlah yang dimanfaatkan untuk mengukur kadar boraks menggunakan alat spektrofotometer UV-Vis (Denny 1994). Salah satu pereaksi yang digunakan yaitu kurkumin. Konsentrasi kurkumin yang digunakan sebesar $0,125 \%$ yang berdasarkan penelitian terdahulu bahwa pada kisaran $0,100 \%-0,150 \%$ kurkumin dapat larut sempurna dalam asam asetat tanpa proses penyaringan ( $\mathrm{Sa}^{\prime}$ adah 2016).
Konsentrasi boraks terbesar terdeteksi pada sampel B1 dan terendah pada sampel B2 berturut-turut yaitu $2414.375 \mu \mathrm{g} / \mathrm{mL}$ dan $129.375 \mu \mathrm{g} / \mathrm{mL}$. Sedangkan untuk kontrol positif, konsentrasi boraks terdeteksi pada $3261.875 \mu \mathrm{g} / \mathrm{mL}$. Salah satu faktor yang menyebabkan berkurangnya konsentrasi boraks pada bakso yaitu adanya proses perebusan. Semakin lama proses perebusan bakso, dimungkinkan semakin banyak boraks pada bakso yang larut dalam kuah bakso selama proses perebusan. Hal ini disebabkan karena sifat boraks sendiri yang mudah larut dalam air dan 
kelarutannya meningkat seiring dengan meningkatnya suhu air (Mule 2018).

Terdeteksinya boraks pada sampel bakso mengindikasikan bahwa masih banyak pedagang yang menambahkan boraks pada baksonya agar tahan lama dan menjadi lebih kenyal. Kurangnya edukasi tentang bahayanya boraks menjadi salah satu penyebab masalah tersebut. Konsentrasi boraks yang dapat menyebabkan keracunan yaitu sekitar $5-10 \mathrm{~g} / \mathrm{kg}$ berat badan. Walaupun konsentrasi boraks pada sampel masih dikatakan kecil, namun bila ditinjau dalam segi kesehatan itu tetap tidak baik karena jika terakumulasi dalam tubuh dapat menyebabkan kerusakan organ. Hal ini dikarenakan boraks bersifat toksik bagi sel sehingga berisiko terhadap kesehatan manusia yang mengonsumsi makanan mengandung boraks (See et al 2010).

\section{Hasil Uji Kualitatif Boraks Dengan FT-IR Spektrometer}

Spektroskopi inframerah merupakan salah satu alat yang dapat digunakan untuk menganalisa senyawa kimia. Daerah inframerah sedang $\left(4000-400 \mathrm{~cm}^{-1}\right)$ berkaitan dengan transisi energi vibrasi dari molekul yang memberikan informasi mengenai gugus - gugus fungsi dalam molekul tersebut. Hasil dari spektrum yang dihasilkan berupa absorbansi maupun transmitan yang merupakan sidik jari dari molekul yang dianalisa. Setiap daerah sidik jari dari suatu sampel hanya menandai 1 struktur molekul pada spektrum IR yang sama.
Alat FT_IR Spektrometer tipe IS5 yang digunakan selama penelitian memiliki kelebihan antara lain memiliki data library senyawa dan salah satunya boraks (Tabel 3). Boraks memiliki rumus kimia $\mathrm{Na}_{2} \mathrm{~B}_{4} \mathrm{O}_{7} .10 \mathrm{H}_{2} \mathrm{O}$ dan bila bereaksi dengan air akan berubah menjadi $\mathrm{NaOH}$ dan asam borate. Dalam analisis boraks menggunakan FT-IR spektrometer yang akan dilihat adalah adanya spektrum pada daerah sidik jari yang menunjukkan adanya ikatan kimia antara Boron (B) dengan molekul lainnya.

Devi (2014) dalam penelitiannya tentang spectra boraks menyatakan bahwa pada $1000-1200 \mathrm{~cm}^{-1}$ terdapat asymmetric stretching molekul $\mathrm{BO}_{4}$. Acarali (2015) menyatakan bahwa pada bilangan gelombang $1350 \mathrm{~cm}^{-1}$ terdapat vibrasi pada symmetric dan antisymmetric ikatan antara B - O. Ersan et all (2015) dalam penelitiannya menyatakan bahwa pada bilangan gelombang $1420-1339 \mathrm{~cm}^{-1}$ menunjukkan adanya asymmetric stretching vibration pada trihedral $\mathrm{BO}_{3}$, 1174 - $1058 \mathrm{~cm}^{-1}$ menunjukkan adanya asymmetric stretching vibration pada tetrahedral $\mathrm{BO}_{4}$, pembengkokan symmetric stretching vibration trihedral $\mathrm{BO}_{3}$ pada $1058-924 \mathrm{~cm}^{-1}$. Hal ini menunjukkan bahwa derah sidik jari untuk senyawa boraks berkisar antara bilangan gelombang $1420 \mathrm{~cm}^{-1}$ sampai $924 \mathrm{~cm}^{-1}$. Data tersebut diperkuat oleh gambar 2 yang menunjukkan bahwa pada bilangan gelombang $1500 \mathrm{~cm}^{-1}$ sampai $1000 \mathrm{~cm}^{-1}$ terdapat perbedaan spektrum boraks pada berbagai konsentrasi boraks.

Tabel 3 Data Library Standar Boraks pada FT-IR Spektrometer

\begin{tabular}{|l|l|l|}
\hline Index & Match & Compound name \\
\hline 448 & $\mathbf{4 1 , 4 1}$ & Borax \\
\hline 25 & 35,19 & POLY(BUTADIENE) + NAPHTHENIC OIL \\
\hline 98 & 34,72 & $\begin{array}{l}\text { ACRYLONITRILE/BUTADIENE COPOLYMER, ACRYLONITRILE CONTENT } \\
19-22 \%\end{array}$ \\
\hline 36 & 32,94 & ETHCHLORVYNOL ON NACL PLATES \\
\hline 73 & 31,86 & beta-Cyclodextrin \\
\hline 60 & 31,56 & Corn Starch, B700 \\
\hline 191 & 31,50 & CHLORZOXAZONE IN KBR \\
\hline 155 & 30,48 & CHLORAL BETAINE IN KBR \\
\hline 69 & 28,05 & Corn Syrup Solids, M365 \\
\hline 429 & 27,52 & Ammonium biborate \\
\hline
\end{tabular}




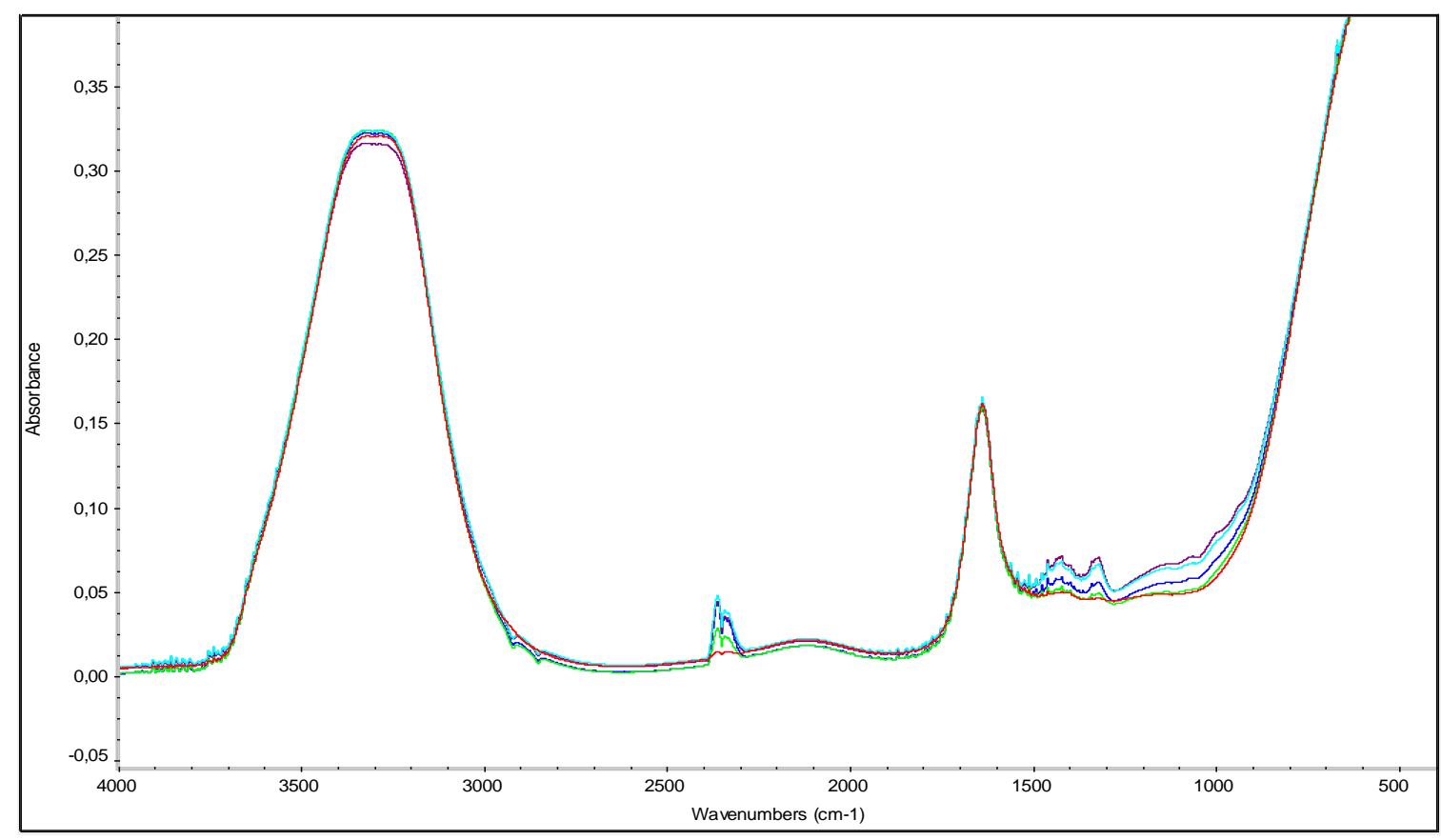

Gambar 2. Spektrum boraks berbagai konsentrasi ; garis ungu $\left(10^{5} \mu \mathrm{g} / \mathrm{mL}\right)$, garis biru muda $\left(8 \times 10^{4} \mu \mathrm{g} / \mathrm{mL}\right)$, garis biru $\left(6 \times 10^{4} \mu \mathrm{g} / \mathrm{mL}\right)$, garis hijau $\left(4 \times 10^{4} \mu \mathrm{g} / \mathrm{mL}\right)$, garis merah $\left(2 \times 10^{4} \mu \mathrm{g} / \mathrm{mL}\right)$

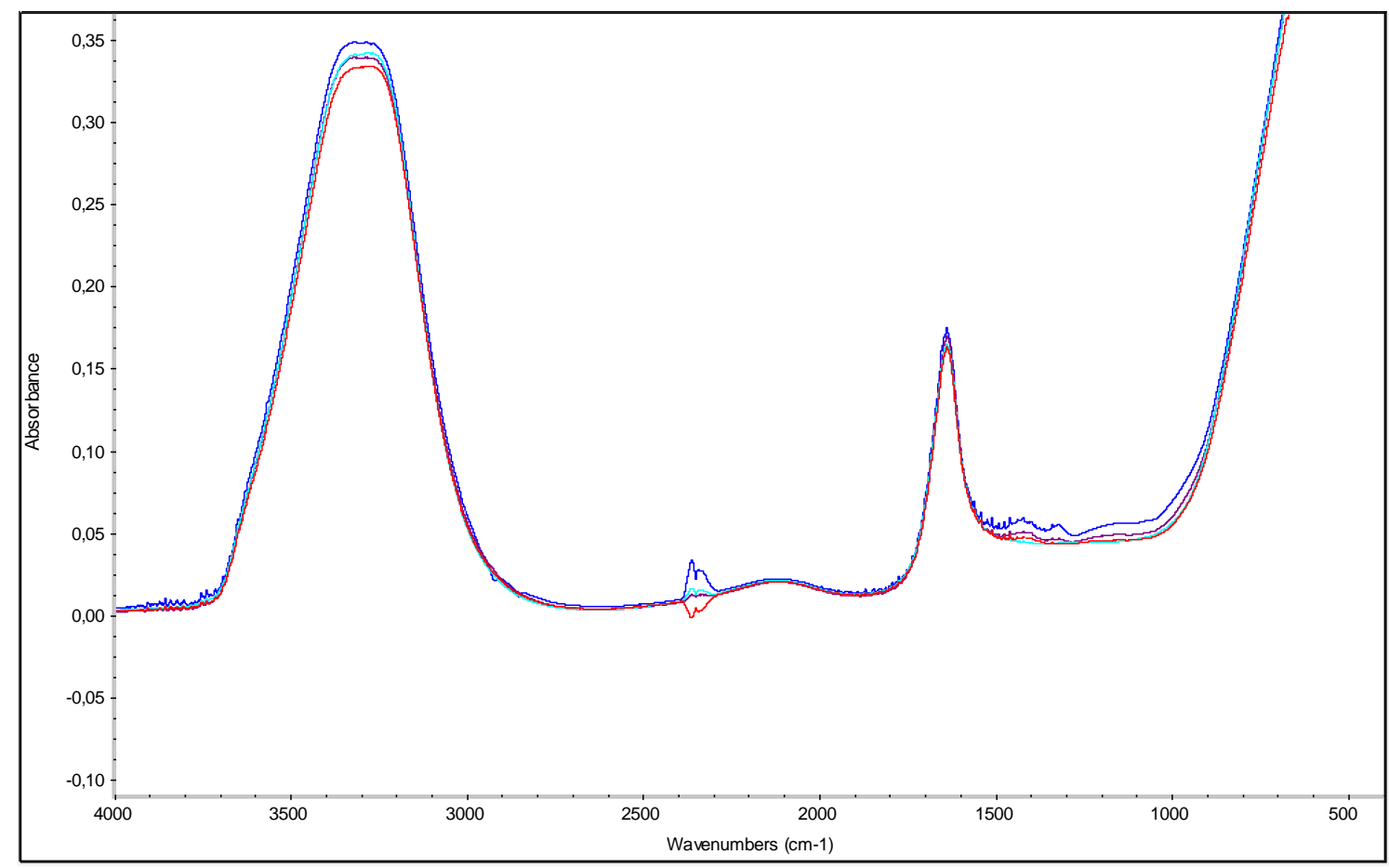

Gambar 3. Spektrum boraks berbagai konsentrasi dan air; garis biru tua $\left(4 \times 10^{4} \mu \mathrm{g} / \mathrm{mL}\right)$, garis ungu $\left(2 \times 10^{4} \mu \mathrm{g} / \mathrm{mL}\right)$, garis merah $\left(1 \times 10^{4} \mu \mathrm{g} / \mathrm{mL}\right)$, garis biru muda (air) 


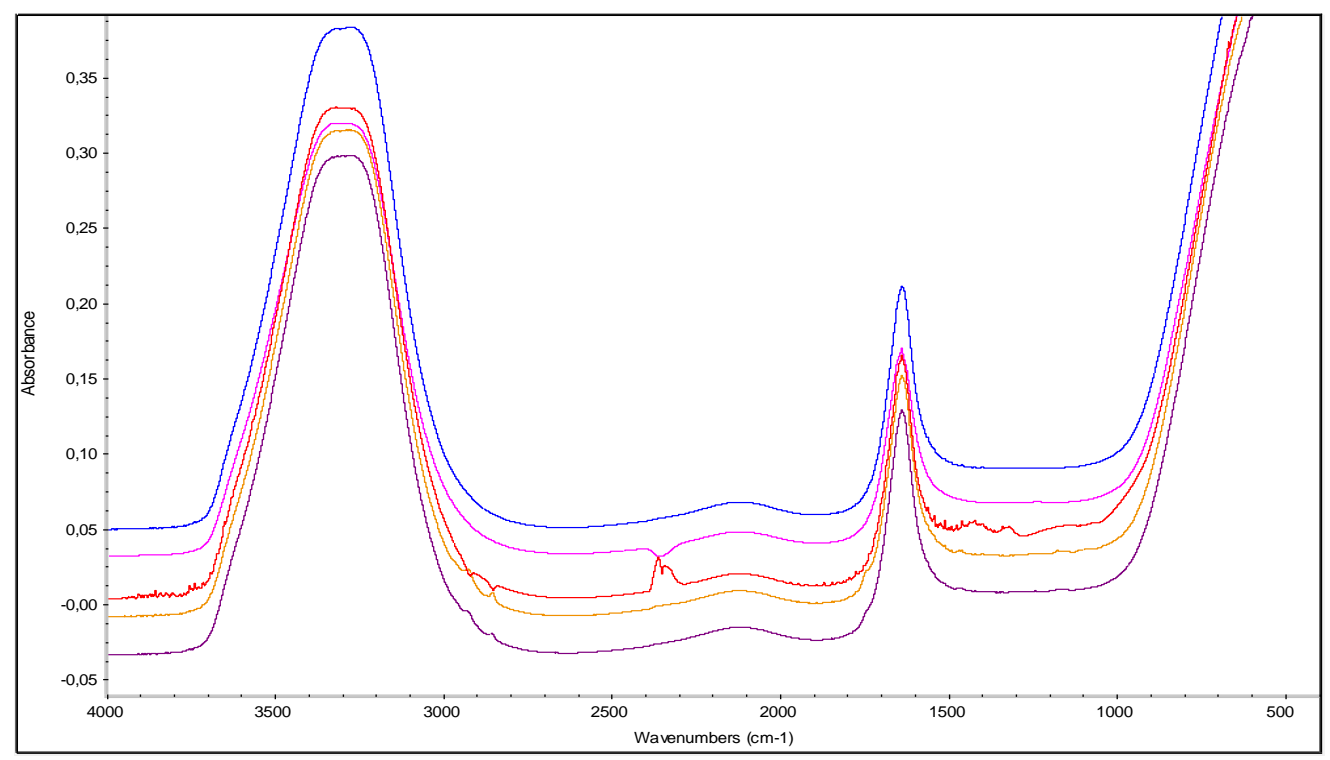

Gambar 4. Spektrum sampel bakso dan boraks ; garis biru ( K-), garis merah muda (air), garis merah (boraks $4 \times 10^{4}$ $\mu \mathrm{g} / \mathrm{mL})$, garis kuning ( $\mathrm{B} 1)$, garis ungu $(\mathrm{K}+)$

Gambar 3 dan 4 menunjukkan bahwa alat FT-IR yang digunakan tak mampu membaca boraks dengan konsentrasi di bawah $4 \times 10^{4} \mu \mathrm{g} / \mathrm{mL}$. Hal ini dapat dilihat dari tidak berbedanya spektrum boraks dengan konsentrasi $2 \times 10^{4} \mu \mathrm{g} / \mathrm{mL}$ dan spektrum air. Bila dibandingkan dengan limit deteksi alat dimana bisa membaca konsentrasi boraks minimum $2 \times 10^{4} \mu \mathrm{g} / \mathrm{mL}$

\section{DAFTAR PUSTAKA}

Acarali NB. 2015. Characterization and Exergy Analysis of Triphenyl Borate. J. Chem.sos.Pak. 37 (4) : $696-703)$.

Aminah dan Himawan. 2009. Bahan-Bahan Berbahaya dalam Kehidupan. Salamadani : Bandung

BPOM . 2014. Waspada Boraks dan Formalin Bahan Berbahaya Pada Pangan. Jakarta.

Denny.R.C. 1994. Vogel-Kimia Analisis Kuantitatif Anorganik. ed.IV. Jakarta: EGC, 809.

Depkes R.I, dan Dirjen POM. 1988. Peraturan Menteri Kesehatan RI Nomor 722/Menkes/Per/IX/1988 Tentang Bahan Tambahan Makanan. Jakarta

Devi SA, Philip D, Aruldhas G. 1994. Infrared, Polarized Raman, and SERS Spectra of Borax. Journal of SOLID STATE CHEMISTRY. 113 : $157-162$. maka saat membaca spektrum sampel bakso B1 maupun sampel bakso kontrol positif, spektrumnya tak akan berbeda dengan spektrum air. Hal ini dikarenakan konsentrasi sampel bakso B1 dan sampel bakso kontrol positif dibawah $2 \times 10^{4} \mu \mathrm{g} / \mathrm{mL}$ yaitu sebesar 2414.375 $\mu \mathrm{g} / \mathrm{mL}$ dan $3261.875 \mu \mathrm{g} / \mathrm{mL}$.

Ersan A, Kipcak AS, Yildirim M, Erayfaz AM, Derun EM, Tugrul N, Piskin S. 2015. Determination of the Zinc Oxide and Boric Acid Optimum Molar Ratio on The Ultrasonic Synthesis of Zinc Borates. Journal of Chemical and Molecular Engineering. 9 (12) : $1444-1447$

Fuad NR. 2014. Identifikasi Kandungan Boraks Pada Tahu Pasar Tradisional di Daerah Ciputat. [skripsi]. UIN Syarif Hidayyatullah Jakarta: Jakarta

Halim, Azhar A. 2012. Boron Removal From Aquaous Solution Using Curcumin-Aided Electrocoagulation. Middle-East

Journal of Scietific Research. 11(5) : 583-588.Hartati FK. 2017. Analisis Boraks Secara Cepat, Murah dan Mudah Pada Kerupuk. Jurnal Teknologi Proses dan Inovasi Industri. 2 (1) : 33 - 37.

Holler. 2002. Official Method of Analysisof the Association of official Analytical .Chemist International, 17thed.AOAC Inc; USA. 
Kresnadipayana D, Lestari D. 2017. Penentuan kadar boraks pada kurma (Phoenix dactylifera) dengan metode Spektrofotometer UV - Vis. Jurnal Wiyata . 4(1): $23-30$.

Mule Team. 2018. Borax Decahydrate. https://www.borax.com/BoraxCorp/media/Bora x-Main/Resources/Data-Sheets/boraxdecahydrate.pdf. [21 Mei 2019].

Panjaitan L. 2010. Pemeriksaan dan Penetapan Kadar Boraks dalam Bakso di Kotamadya Medan. http://Repository.usu.ac.id/bitstream/123456789 /17273/ 7/Cover.pdf [13 Februari 2018].

Rumanta M, Ratnaningsih A, Iryani K. 2014. Analisis Kandungan Boraks Pada Jajanan Pasar di Wilayah Kecamatan Pamulang, Tangerang Selatan. Laporan penelitian Fundamental UT Lanjut.

Rusli R. 2009. Penetapan Boraks Pada Mie Basah Yang Beredar Di Pasar Ciputat Dengan Metode Spektrofotometer UV -VIS Menggunakan Pereaksi Kurkumin. [skripsi]. UIN Syarif Hidayyatullah Jakarta: Jakarta

Sa'adah, L. 2006. Identifikasi Boraks dan Asam Borat pada Beberapa Jenis Mie yang Diperoleh dari Pasar Depok. [Skripsi]. Universitas Indonesia : Depok.

See AS, Salleh AB, Bakar FA, Yusof NA, Abdulamir AS, Heng LY. (2010) Risk and health effect of boric acid. Am. J. Appl. Sci. 7(5):620-627.

Svehla, G. 1985. Buku Teks Analisis Anorganik Kualitatif Makro dan Semimikro, Terjemahan: Setiono dan A. Hadyana Pudjatmaka. Jakarta: PT. Kalman Media Pustaka

Widayat D. 2011. Uji Kandungan Boraks Pada Bakso . [skipsi]. Universitas Jember : Jember

Widyaningsih TD, Murtini ES. 2006. Alternatif Pengganti Formalin Pada Produk Pangan. Jakarta: Trubus Agrisaran

Zeng L M, Wang H Y, Guo Y L. 2010. Fast Quantitative Analysis of Boric Acic by Gas Chromatography Mass Spectrometry Coupled with a Simple and Selective Derivatization Reaction Using Triethanolamine. J Am Soc Mass Spectrom. 21: $482-485$. 